\title{
PRECAST CONCRETE BUILDING CONSTRUCTION PROCESS COMPARISON
}

\author{
Tian Xiaosheng' ${ }^{1}$ and Farook Hamzeh²
}

\begin{abstract}
Research shows that the precast construction process comprises waste and excessive lead times. The application of Lean Construction principles within the precast construction process varies from country to another due to different regional codes, market demands, informatics tools, fabrication and erection method, etc. This paper deploys value stream mapping (VSM) as a lean methodology to investigate and compare the process differences between a Canadian precast project and a Chinese precast project as basis for improvements in reducing process waste. A framework of comprehensive future state mapping is proposed based on the application of advanced technologies advised by industry 4.0 to guide future precast projects towards a lean process value flow.
\end{abstract}

\section{KEYWORDS}

Precast concrete; Lean construction; Process; Value stream; off-site construction

\section{INTRODUCTION}

The precast concrete industry, especially in developing countries, suffers from several problems including long lead times, unsmooth flow, and embedded process waste. Much research indicated the indispensability of improving flow or process in the construction industry to improve productivity, productive time ratio, quality and project team commitment (Ballard 1999; Chen et al. 2003; Serpell et al. 1996). To implement lean concepts in the precast concrete industry, one of the most economical, environmental and social friendly sectors of the construction industry (Li et al. 2014), many researchers have worked on identifying and improving flow to eliminate waste in the process (Ballard et al. 2003; El Sakka et al. 2016; Ergen and Akinci 2008; Pan et al. 2012; Sacks et al. 2003). Several studies have compared the different purposes (Li et al. 2014), limitations (Polat 2010) and construction techniques ( $\mathrm{Li}$ et al. 2019) of precast concrete construction between developed countries and developing countries. There is little research that focuses on comparing flow aspects or process status of precast concrete construction between developing countries and developed countries. This research compares two processes on two projects in different countries, one in Canada and one in China. Using case study analysis, this study employs value stream mapping to identify waste and value loss, and then suggests future directions to optimize the process using lean principles.

1 Graduate Student, Civil and Environmental Engineering Department, University of Alberta, Canada, xtian4@ualberta.ca, orcid.org/0000-0003-1949-850X

2 Associate Professor, Civil and Environmental Engineering Department, University of Alberta, Canada, hamzeh@ualberta.ca, orcid.org/0000-0002-3986-9534 


\section{LITERATURE REVIEW}

Lean thinking is regarded as the elimination of waste and the increase of value (Womack and Jones 1996). With a focus on value, value stream, flow, pull and perfection (Womack and Jones 1996), the lean concept has been widely accepted and implemented across several industries showing improvements in performance (Shah and Ward 2003). Flow in lean can be regarded as a combination of information and resource flows, as well as a process flow. Seymour (1996) has discussed the importance and changes of the flow when applying lean concepts in the construction industry. Picchi's research interpreted the flow in construction into three sectors, business flow with a sub-flow of design, supply flow and job site flow (Picchi 2000). The flow within a process in construction is the place where most waste occurs, and improvements should be implemented (Serpell et al. 1996).

Much research has been conducted to identify methodologies to improve the flow within a process in the construction industry. Serpell has developed a general structured framework with cyclical activities to identify and implement improvements in the construction process, which effectively lead to direct benefits of increased productivity and productive labour time, reduction of rework, and better quality (Serpell et al. 1996). Ballard's research has shown a 52\% productivity improvement when workflow reliability has been improved by several proposed actions (Ballard 1999). An information flow integrated process modeling has been developed to synchronize the information flow with the construction process (Chen et al. 2003). Al Hattab and Hamzeh (2018) studied information flow during design and identified causes of disruptions.

Due to benefits of precast concrete compared with in-situ concrete, such as durability, greater span-to-depth ratios, accelerated construction, weather tolerable construction, minimum material usage, minimum waste, etc. (CPCI 2017), precast concrete has been implemented worldwide in many different construction structures including: bridges, parking garages, commercial buildings and multi-family residential apartments.

Lean is also a hot topic in the precast industry. With the precast components manufactured in the plant, it has more similarities with the manufacturing industry where lean concepts was first introduced. Ballard's research improved workflow in a precast plant by increasing workers' and plants' productive time to reduce the shop cycle time and lead time, while increasing production rate and productivity. A new process flow for precast was created utilizing value stream mapping to identify value-added processes and wastes, and a smoother process with shorter lead time was observed during the research. (Ballard et al. 2003). Sacks' research on the precast construction process has indicated that 3D modelling can reduce the long engineering buffer time (Sacks et al. 2003). A CTRAUS matrix was developed to illustrate the information flow in the precast industry identifying patterns and optimization opportunities of information flow for further decision making on which methods or technologies should be used to collect data and manage the process (Ergen and Akinci 2008). Pan's research on a precast building case study indicated that early involvement and integration of an off-site strategy could maximize business efficiency (Pan et al. 2012). Sakka et al. utilized VSM to study the process of pre-slabs in a precast plant. Results indicated that continuous improvements are possible when applying lean concepts in a precast plant to decrease lead time, reduce waste and improve safety (El Sakka et al. 2016).

Developing countries are gradually paying more attention to precast research as construction is still their main economic activity ( $\mathrm{Li}$ et al. 2014). Li's research indicated different interests in precast concrete among those countries. Developed countries adopt precast concrete as an economic, environmental and social-friendly construction method 
while developing countries focus on its sustainable benefit for their high demand in rapid urbanization ( $\mathrm{Li}$ et al. 2014). Polat investigated the different leading causes of low market share of precast concrete for developed and developing countries (Polat 2010).

Limited amount of research focuses on the application of precast concrete in residential buildings ( $\mathrm{Li}$ et al. 2014). The amount of research on the "process" facets is less than the "product" facets and more research attention should be devoted to strategic areas to enhance the industrialized building concept (Hosseini et al. 2018). Although momentous efforts have been contributed by previous researchers, very little research has focused on comparing precast concrete processes and differences in flow between developed and developing countries.

This research investigates the difference in the precast process for multi-family building construction in China and Canada. The objectives of the case study are to identify the process differences, to suggest steps to eliminate waste in the process, and to develop an improved process framework to better apply lean concepts in the precast concrete industry.

\section{METHODOLOGY}

Case study analysis is deployed in this research to answer questions about "how" and "why" process differences occur in selected cases.(Yin 2017). Value stream mapping, developed from the Toyota production system, is used as a lean tool to study the process in the two cases (Rother and Shook 2003). The value stream shows the process of delivering the product through flows with value-added activities and non-value-added activities. Value stream mapping shows the process from the supply of material to the demand of the product, the information flows at the top of the chart, and the material flow at the bottom.

In this research, value stream mapping is employed to present the material flow and information flow of design-related activities during the precast building construction process from the initial design till field erection. Flows of material and information are compared between the two selected case projects in China and Canada.

The level of implementing lean for each case project is discussed and compared, followed by future state mapping for both case projects. By analyzing the advantages and disadvantages of both case projects, a framework of a comprehensive future state map is proposed as a suggestion for the future precast projects.

\section{PRECAST CONSTRUCTION VALUE STREAM MAPPING}

This research focuses on the lean measure of the precast concrete project processes and the differences between two selected case projects based in different countries. To compare the processes, two multilevel precast projects are selected, one is based in Alberta, Canada, the other is in Beijing, China. The two case-study projects were chosen for: 1) fit as both were executed by the local large precast supplier (PS) and 2) convenience as the project information was accessible. Both project implementation methods are typical of their PS and have some representativeness nationwide. Because the research investigates the process lean measure on a broader scale, only typical activities that represent the critical material and information transmission are depicted. Although different informatics tools and contract formats are used, the process is mainly the same, starting from initial modelling/drawing, to developing precast shop drawings, shop drawings modification, precast production, transportation, and erection. The main 
differences are the time at which the PS is involved on the project, design methodology, and the efficiency.

\section{CURRENT STATE MAPPING OF THE AlbERTA PROJECT}

The current state map of the Alberta project is shown in Figure 1. The Canadian PS is the contractor responsible for the whole lifecycle work from initial modeling until the site erection. Although the PS had achieved some improvements in efficiency by early participation in the project design and using a 3D model instead of 2D drawings to reduce the total design time, some processes still need optimization.

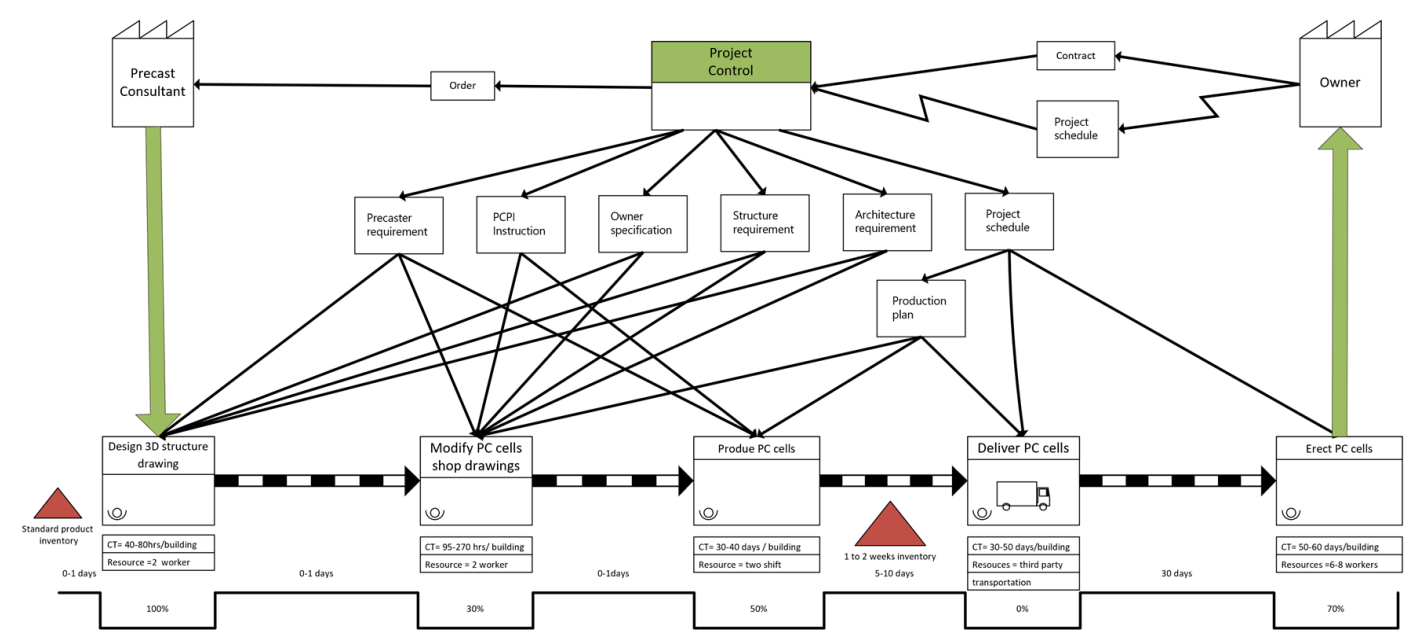

Figure 1: Current state mapping for the precast project in Alberta

- Although the shop drawings could be exported directly from the 3D model, extra work for shop drawing modification was still needed to meet the production requirement. Ranging from simple components to complex ones, 5 minutes to 1.5 hours was needed to modify each drawing.

- The lead time between the production and delivery could be 1 to 2 weeks. Those completed products required space to store, needed extra maintenance and management to avoid damage, and impeded the implementation of FIFO. What's important is that there were a large number of assets that didn't produce any value during the lead time.

- The lead time before erection was one-month long, which was caused by the slow production rate and the fast erection rate. To keep a high productivity and reduce the on-site idle time, lots of finished precast members were stored at the construction site one month before erection. Extra management and maintenance were needed for a large amount of inventory, and space was taken up as well. It also resulted in inevitable over-handling, which would cause damage to precast members, and decrease the overall productivity as cranes are limited and valuable resources.

\section{CURRENT STATE MAPPING OF THE BEIJING PROJECT}

The current state map of the precast process in Beijing, China, is shown in Figure 2. The PS is a subcontractor who works for the contractor where the process includes only 
detailed design and fabrication drawings as the $2 \mathrm{D}$ initial drawings were provided. With late participation of the PS in the process, the lead time is much longer.

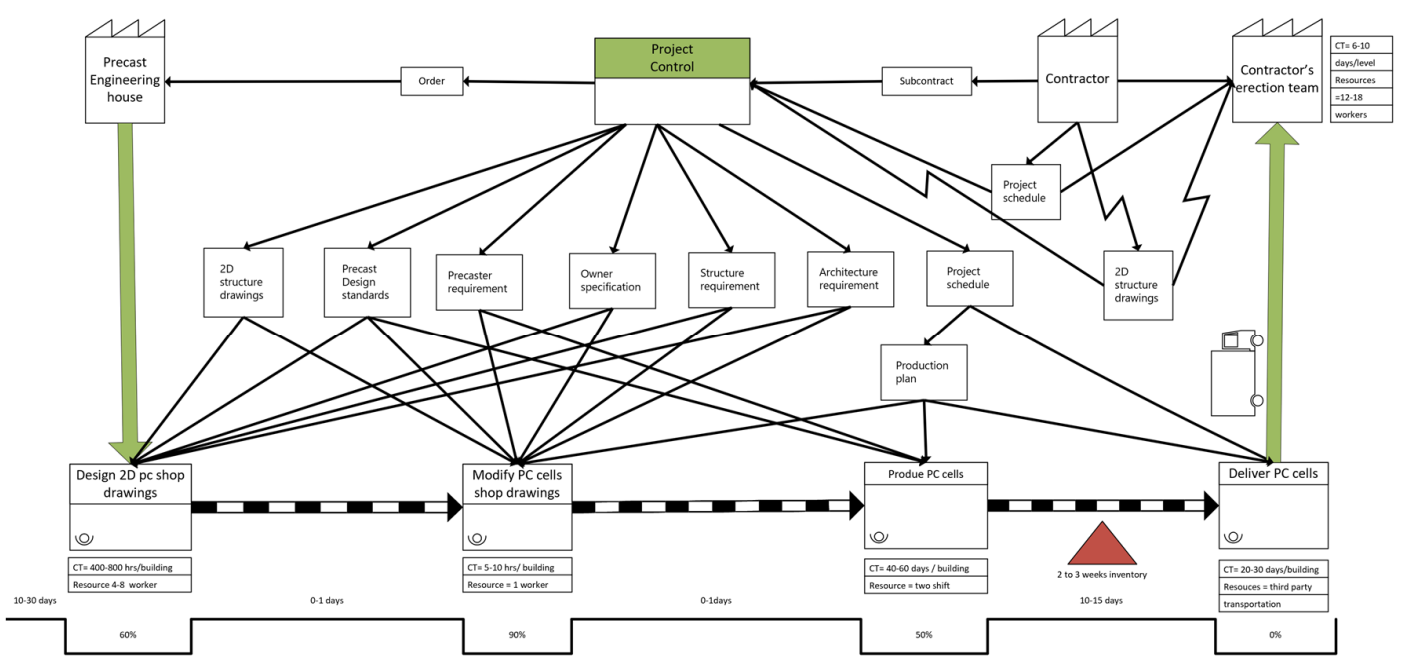

Figure 2: Current state mapping for the precast project in Beijing

- Long lead times before the start of shop drawings is due to the subcontract agreement. The PS couldn't start the detailed design until they got the approved 2D initial drawings from the contractor, and any changes in the initial drawings increased the lead time due to extra times for review and approval.

- The duration of the precast detailed shop drawings process is long. Each of the precast members needed to be redesigned to illustrate the size, location and quantity of rebars, windows, doors and other accessories. It's time-consuming job when design is conducted using the traditional method of developing 2D-drawings. Each drawing took 2 to 8 hours on average to be completed.

- Long lead times were also present between production and delivery. Because the erection work was not performed by the PS, with indirect communication between precast production plan and updated construction plan, the PS had to prepare more products to meet the changing schedule. This resulted in more inventory, more maintenance, and a more constrained cash flow.

- The complex connection method increased the erection duration. With the consideration of the anti-earthquake requirement, most Chinese precast residential buildings used the 'wet connection' instead of the 'dry connection'. All precast members need to be connected using cast-in concrete. The methodology required additional concrete work, labour, extra formwork, curing, and safety hazards.

\section{COMPARISON OF THE CURRENT STATE PROCESSES}

When comparing to the two case projects, both have some lean construction features:

- Early involvement on the project benefited the Canadian PS when working with the project team, including architect, the structural engineer, and the owner. The BIM-based 3D model guaranteed a short lead time, and simplified the process of shop drawings as they could be exported directly from the model. Structural modifications can be reflected on the shop drawings automatically, so no rework on shop drawings was needed. 
- Some of the precast members are standardized and can be used in different projects which benefits the Canadian PS with a shorter lead time. Only customized products need a new design and in-time production. Standard precast members in high demand can be made-to-stock to reduce delays during the peak production.

- Participation of the Canadian PS in the whole life cycle improved the entire schedule and increased productivity. The PS and the client worked together from the beginning of the design until the final erection, keeping the whole process smoother.

- Instead of hiring a third-party engineering firm as a consultant for the Canadian PS, the Chinese PS has its own in-house engineering capability. Some Engineers had work experience in the precast factory and had a deeper understanding of the production requirement of drawings. With smoother communication within the enterprise, the shop drawings could satisfy the production requirement, and only some small changes were needed later.

\section{FUtURE STATE MAP OF THE Alberta PROJECT}

A future state map is proposed to include several lean features with several Kaizens as shown in Figure 3.

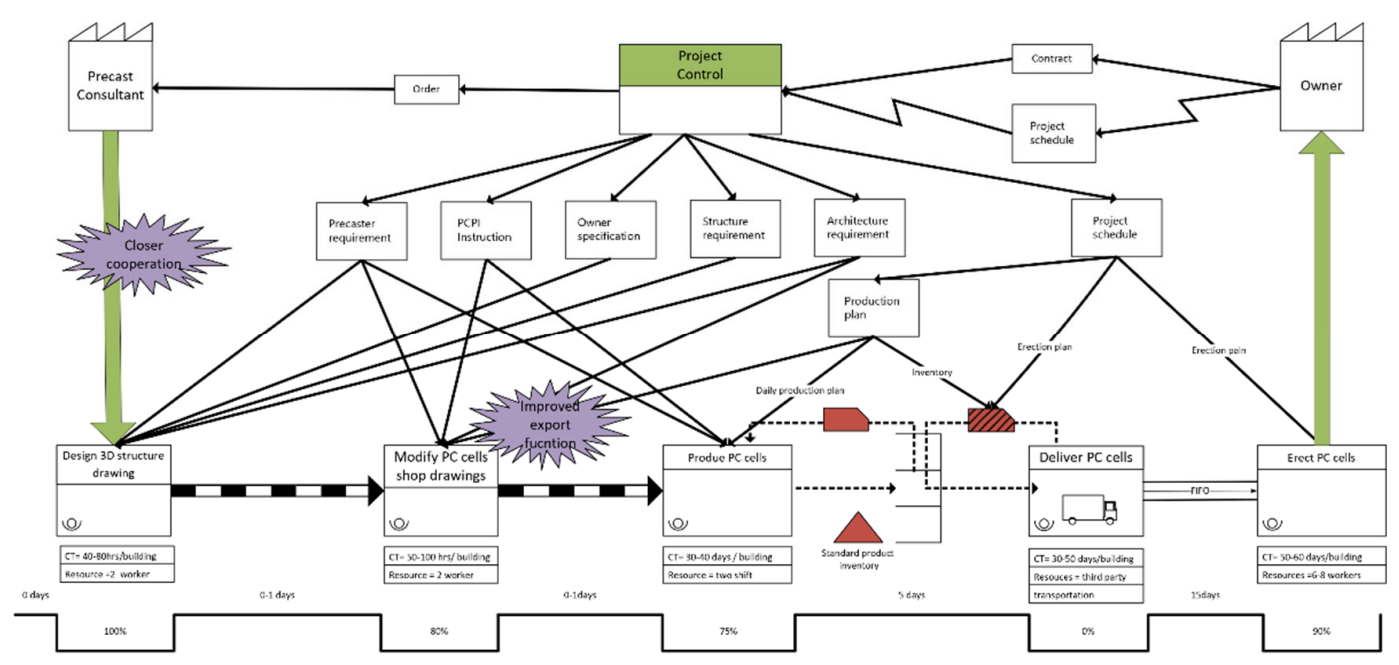

Figure 3: Future state mapping for the precast project in Alberta

Closer cooperation indicates that the PS and consultant need to enhance their cooperation. One suggestion is that the Canadian PS can set up its own engineering house. Both model design and shop drawings modification can be completed inhouse with full understanding of the production requirements.

The export function inside the precast 3D modelling software needs to be improved. Additional modification consumed 5 minutes to 1.5 hours for each drawing in the project, and it's a common problem for precast concrete design software, including the widely used Revit. It is valuable to improve the autonomous and localized precast design functions of BIM software as well as to integrate these capabilities with planning and production system.

A supermarket is introduced between production and delivery to reduce the lead time. Precast concrete weekly production plan will synchronously collaborate with the site 
erection plan. The erection team will request deliveries through the withdraw Kanban, once precast units are shipped from the supermarket, a production Kanban will be released to supplement the supermarket vacancy. And the production plan is designed to ensure the inventory of the supermarket have enough buffer to satisfy the erection requirement, which is roughly 5 days of production capacity. . Applying a supermarket can transform the push process into a partial pull system. And the lead times will decrease from 2 weeks to 1 week. To achieve the ideal situation, the factory has to level the production among different product types, and different projects demand. The trade-off between change over time and customer demand is a suitable solution. Also, applying first in first out (FIFO) can reduce the damages of precast members caused by poor maintenance and over handling.

Ballard has proposed a lean method which introduces a buffer before the fabrication as a make-ready period and produces precast members as per erection requirements one week before delivery while the customer order for all products are already placed to reduce demand variability (Ballard et al. 2003), which is similar to a supermarket where fabrication is controlled by the demand Kanban to convert the process into a pull system.

\section{FUTURE STATE MAP OF THE BEIJING PROJECT}

Figure 4 shows the future state map of the Chinese precast construction process. To solve the long design duration problem, applying BIM can improve the overall productivity and save costs. With the 3D model, the overall design duration has dramatically decreased. Shop drawings can easily be exported from the 3D model. Some software, such as Tekla structure, Revit, Planbar and PKPM-PC, can provide similar functionality to build the rich-information 3D model, and export the required drawings. While the precast methods and standards differ between countries, special customization and optimization are needed for the software.

The PS need to convert its attitude from a passive subcontractor to a positive project team member to drive the BIM design process. Rework on shop drawing caused by the structural changes can be avoided. Some other issues can be eliminated as well, such as design omissions, design conflicts, paperwork, etc.

Standardized precast design can also improve the precast process. Caused by the castin concrete connection method and the PS late involvement in the precast design, the reusage rate of the precast design and molds are significantly low. To improve design standardization, a universal precast standard, including structural design, connection design, should be established by official institutions. Early participation in the project can help the PS gain more influence in the process.

A shared project schedule is critical to communicate between the production plan, inventory, and erection plan. Introducing a supermarket can convert the push process into a partial pull system. The supermarket is a solid buffer not only to protect the supply for a particular project but also increasing resource utilization and satisfying all customers to maximize the achievable value (Mao et al. 2015) 


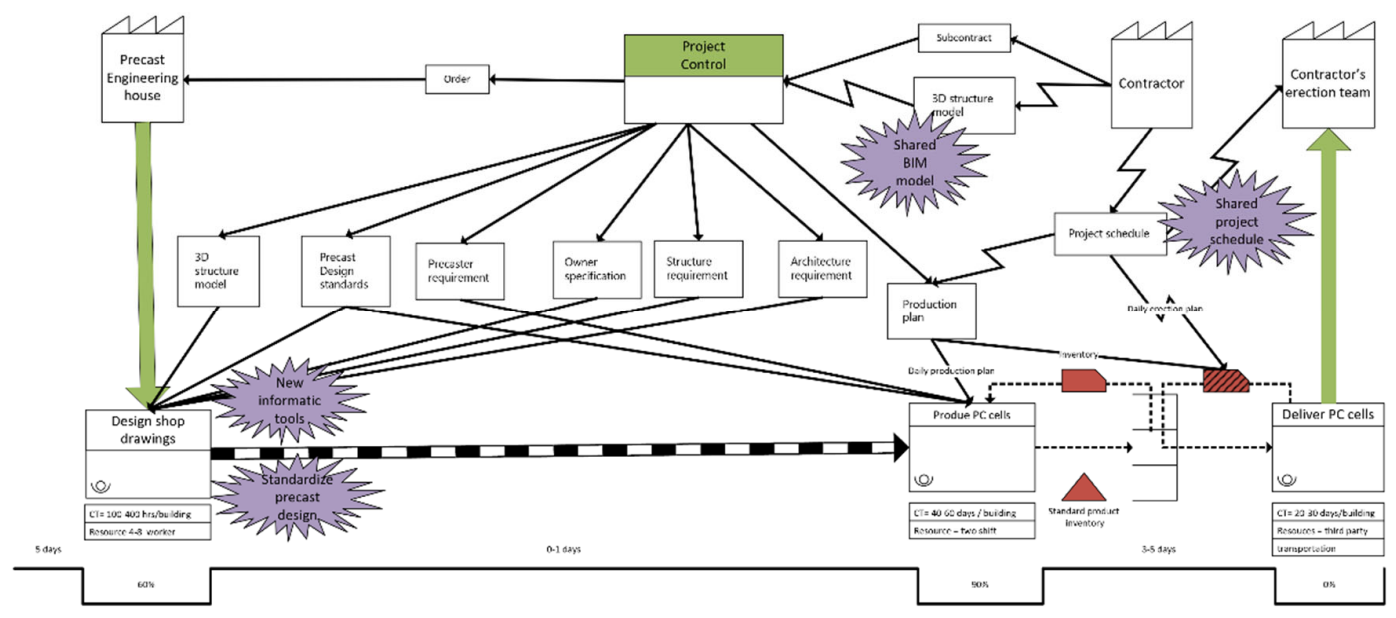

Figure 4: Future state mapping for the precast project in Beijing

\section{A FUTURE STATE MAPPING FOR THE PRECAST CONSTRUCTION PROCESS}

Industry 4.0 is regarded as a new system to increase productivity and reduce waste. Simulation, Building Information Modeling (BIM), augmented/virtual/mixed reality, automation, radio-frequency identification (RFID) and cloud computing are the most popular applications of industry 4.0 in the construction industry (Oesterreich and Teuteberg 2016). A comprehensive future state map of the precast construction process is proposed by exploiting those advanced technologies to reduce waste further and make the process more lean.

As is shown in Figure 5, production and erection are managed by a BIM and lean integrated production system. It uses rich information from the BIM model and productivity benchmarks as inputs and extracts required information to work with an enterprise resource planning system (ERP) to plan and control the project processes in a lean management method to reduce waste and maximize resource utilization. Project schedule and cost simulation are typical features that result in a more reliable schedule to reduce lead time and increase resource utilization. Moreover, the accurate cost estimation can lead to a cost-saving and quality-guaranteed project as well as a more significant profit margin for the PS.

Some researchers have worked on integrating BIM and lean to form a production system. BeaM! is proposed as an integrated production system of both BIM and lean philosophy, which uses the digital Kanban board to communicate the BIM processing data with the last planner system (Schimanski 2019). Dallasega has introduced a decentralized and pull-based control loop in the construction engineering-to-order supply chain, which has been tested to benefit the project with labor-saving, on-time delivery, and early identified problems (Dallasega et al. 2016).

Product lifecycle management (PLM) can be applied to the precast members with the radio-frequency identification (RFID) technology. Sacks has proposed a precast production database to collect information from production to erection to reduce the time buffer and reduce the information exchange barriers (Sacks et al. 2003). While applying BIM to build the 3D model, each piece of precast can be linked to an RFID tag to monitor its flow in the value chain (Akinci et al. 2003; Montaser and Moselhi 2014; Yoon et al. 2006). Better management can be achieved as more data is gathered by those sensors for schedule adjustment and decision making. 


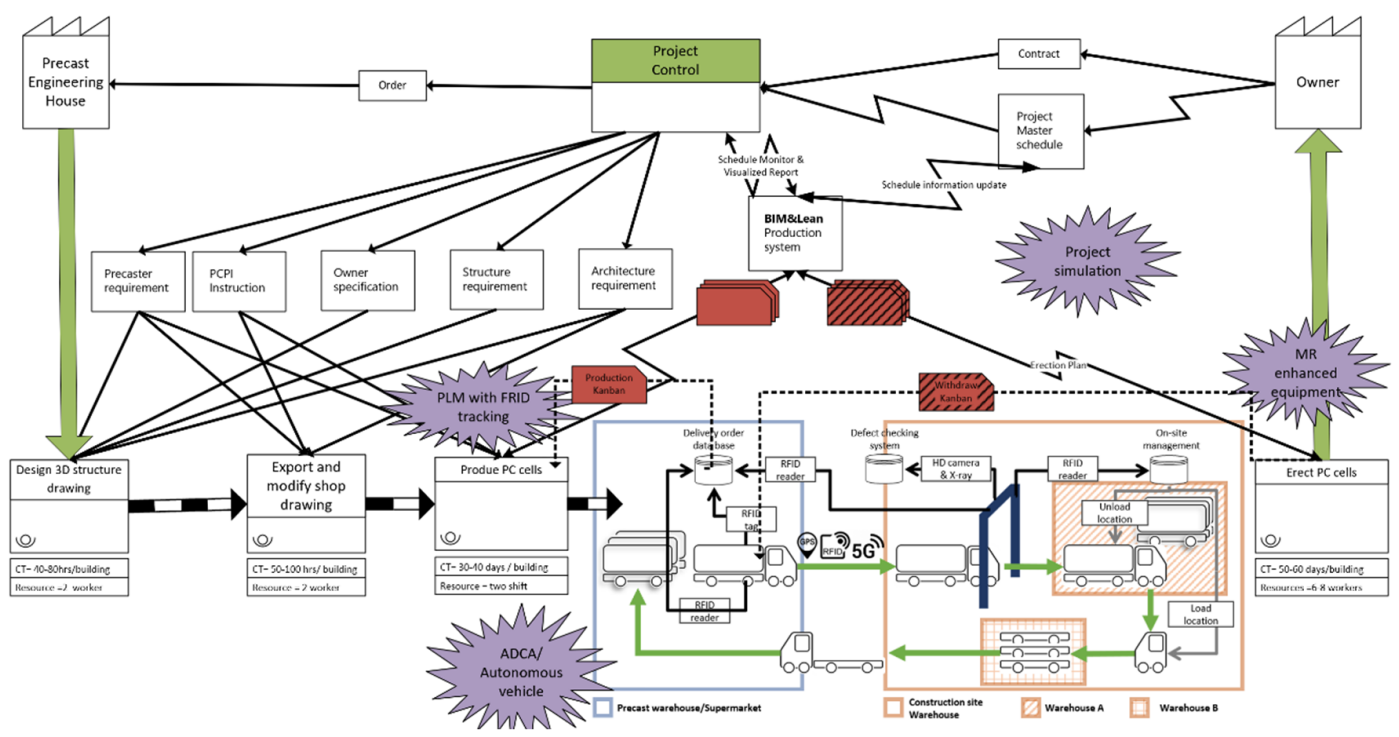

Figure 5: Comprehensive future state mapping of the precast construction process

Autonomous vehicles could be used in precast construction. Delivering precast members requires a larger space, longer distance, and higher cost compared with cast-in concrete . Applying autonomous vehicles can reduce the logistic cost because of the lower labour cost, lower insurance cost, larger vehicle utilization rate, and shorter delivery time. In collaboration with RFID and other IoT technologies, it can improve productivity as well. A framework of autonomous delivery/ check/ acceptance system (ADCA) is proposed which utilizes RFID to check and track delivery information and distinguish the appearance and quality defects from pitchers captured by HD camera and X-Ray. It can reduce labour and also crane over handling to increase productivity.

To further improve the onsite erection productivity, virtual reality (VR) or augmented reality (AR) can be used as a training method to educate and assess the workers' skills as the interactive training has better performance (Boud et al. 1999). For the onsite erection, mixed reality (MR) can be used as an assisting technique to support the work and increase the work efficiency and quality. Workers equipped with MR devices can read precast IDs, and additional information such as member information, erection instruction, and safety tips can be shown in the worker's vision to guide the processing activity.

To help a PS apply lean to improve their production process is a complex process that requires experts with experience and knowledge in lean manufacturing and construction. Some projects have introduced an expert Team PS to optimize their production, increase resource utilization, productivity, quality with lean tools including JIT, Kanban, 5S and cellular plant layout t (Deffense and Cachadinha 2011). Research has shown that experienced experts are critical to the success of lean improvements for a PS (Ko and Ko 2009). Hence, reducing the knowledge barriers between manufacturing and construction, educating students in in lean construction philosophy and tools can help groom future precast construction experts.

\section{CONCLUSION}

This research has investigated and compared the current processes of the two selected precast construction projects in Canada and China. On one hand, The comparison results show that the project in Canada has less rework, shorter lead time, and better productivity 
because of the earlier PS involvement, application of BIM, and higher ratio of standardized precast design. Om the other hand, the project in China has higher quality of shop drawings because of the in-house engineering capability. The case projects both have some room for future improvement. Future state maps of two precast processes are proposed where enhanced cooperation and improved shop drawing export function are suggested to the Canadian PS to reduce the design duration and shorten the lead time, and applying BIM to design precast elements from the project early phase is the solution for the Chinese PS. A supermarket as a temporary inventory is proposed for both PSs to convert the push production process into a partial pull system with withdrawal Kanban to reduce the lead time and inventory. With the combination of new technologies in industry 4.0, a comprehensive far future state map is proposed for future precast projects. Integration of BIM and lean philosophy, using RFID for product lifecycle management, application of autonomous vehicle for delivery, utilizing $V R \backslash A R \backslash M R$ to improve productivity, and grooming future experts with strong knowledge in lean philosophy, are suggested to maximize value and reduce waste for precast construction.

\section{REFERENCES}

Akinci, B., Patton, M., and Ergen, E. 2003. "Utilizing radio frequency identification on precast concrete components-supplier's perspective." NIST Special Pub. SP, 381-386.

Al Hattab, M., and Hamzeh, F. 2018. "Simulating the dynamics of social agents and information flows in BIM-based design." Automation in Construction, 92, 1-22.

Ballard, G. 1999. "Improving work flow reliability." Proceedings of the 7 th Annual Conference of the International Group for Lean Construction. Berkeley, Calif., USA, 275-286.

Ballard, G., Harper, N., and Zabelle, T. 2003. "Learning to see work flow: an application of lean concepts to precast concrete fabrication." Engineering, Construction and Architectural Management, 10(1), 6-14.

Boud, A. C., Haniff, D. J., Baber, C., and Steiner, S. 1999. "Virtual reality and augmented reality as a training tool for assembly tasks." Proc., 1999 IEEE International Conference on Information Visualization (Cat. No. PR00210), 32-36.

Chen, Q., Chua, D. K. H., and Song, Y. 2003. "Information Flow Integrated Process Modeling." Proc. 11th Annual Conferene of the International Group for Lean Construction, Virginia, USA

CPCI 2017. Design Manual. Canadian Precast/Prestressed Concrete Institute, Canada.

Dallasega, P., Marcher, C., Marengo, E., Rauch, E., Matt, D. T., and Nutt, W. 2016. “A decentralized and pull-based control loop for on-demand delivery in ETO construction supply chains." Proc. 24th Annual Conference of the International Group for Lean Construction, Boston, USA. 33-42.

Deffense, J., and Cachadinha, N. 2011. "Lean production in the precast concrete components' industry." Proc. 19th Annual Conference of the International Group for Lean Construction, Lima, Peru, 557-567.

El Sakka, F., Eid, K., Narciss, T., and Hamzeh, F. 2016. "Integrating lean into modular construction: a detailed case study of company X." Proc. 24th Annual Conference of the International Group for Lean Construction, Boston, Mass., USA, 23-32.

Ergen, E., and Akinci, B. 2008. "Formalization of the flow of component-related information in precast concrete supply chains." Journal of Construction Engineering and Management, 134(2), 112-121. 
Hosseini, M. R., Martek, I., Zavadskas, E. K., Aibinu, A. A., Arashpour, M., and Chileshe, N. 2018. "Critical evaluation of off-site construction research: A Scientometric analysis." Automation in Construction, 87, 235-247.

Li, L., Li, Z., Yuan, , and Zhang, S. 2019. "Comparative Study of Industrialized Construction Logic between General Prefabricated and Improved Prefabricated Construction in China." ICCREM 2019: Innovative Construction Project Management and Construction Industrialization, American Society of Civil Engineers, Reston, VA, 669-677.

Li, Z., Shen, G. Q., and Xue, X. 2014. "Critical review of the research on the management of prefabricated construction." Habitat International, 43, 240-249.

Mao, C., Shen, Q., Pan, W., and Ye, K. 2015. "Major Barriers to Off-Site Construction: The Developer's Perspective in China." Journal of Management in Engineering, 31(3).

Montaser, A., and Moselhi, O. 2014. "RFID indoor location identification for construction projects." Automation in Construction, 39, 167-179.

Oesterreich, T. D., and Teuteberg, F. 2016. "Understanding the implications of digitisation and automation in the context of Industry 4.0: A triangulation approach and elements of a research agenda for the construction industry." Computers in Industry, 83, 121-139.

Pan, W., Gibb, A. G., and Dainty, A. R. 2012. "Strategies for integrating the use of offsite production technologies in house building." Journal of Construction Engineering and Management, 138(11), 1331-1340.

Picchi, F. A. 2000. "Lean Principles and the Construction Main Flows." Proc. 8th Annual Conference of the International Group for Lean Construction, Brigthon, UK.

Polat, G. 2010. "Precast Concrete Systems in Developing Vs. Industrialized Countries." Journal of Civil Engineering and Management, 16(1), 85-94.

Rother, M., and Shook, J. 2003. Learning to see: value stream mapping to add value and eliminate muda, Lean Enterprise Institute, USA

Sacks, R., Akinci, B., and Ergen, E. 2003. "3D modeling and real-time monitoring in support of lean production of engineered-to-order precast concrete buildings." Proc. 11th Annual Conference of the International Group for Lean Construction, Virginia, USA.

Schimanski, C. P., Monizza, G.P, Marcher, C., Matt, D.T. 2019 “Conceptual Foundations for a New Lean Bim-Based Production System in Construction." Proc. 27th Annual Conference of the International Group for Lean Construction, Dublin, Ireland, 877888.

Serpell, A., Alarcón, L. F., and Ghio, V. 1996. "A general framework for improvement of construction process." Proc. 4th Annual Conference of the International Group for Lean Construction, Birmingham, UK.

Seymour, D. 1996. "Developing Theory in Lean Construction." Proc. 4th Annual Conference of the International Group for Lean Construction. Birmingham, UK

Shah, R., and Ward, P. T. 2003. "Lean manufacturing: context, practice bundles, and performance." Journal of operations management, 21(2), 129-149.

Womack, J. P., and Jones, D. T. 1996. "Lean thinking-banish waste and create wealth in your corporation." Journal of the Operational Research Society, 48(11), 1148-1148.

Yin, R. K. 2017. Case study research and applications: Design and methods. Sage publications, UK. 
Precast Concrete Building Construction Process Comparison

Yoon, S.-W., Chin, S., Kim, Y., and Kwon, S. 2006. "An application model of RFID technology on progress measurement and management of construction works." Proc. 23rd International Symposium on Automation and Robotics in Construction, 779-783. 